\title{
Fetal Femur Length and Abdominal Circumference Ratio in Bangladesh
}

\author{
SABRINA Q. RASHID
}

\begin{abstract}
Objective: The ratio of fetal femur length and abdominal circumference is one of the important ratios. But we do not have any study on it in our country so far. Therefore a study was conducted to prepare a table based on Bangladeshi population.

Method: Well dated pregnancies were included in a cross-sectional prospective study. By fitting Polynomial regression model a table and a graph were prepared. Nomograms of Caucasian population which were established before, were compared with this study.

Results: A chart of the raw data of 1223 subjects with superimposed fitted percentiles was produced. The quadratic model showed a good fit to the data. $3^{\text {rd }}, 10^{\text {th }}, 50^{\text {th }}, 90^{\text {th }}$ and $97^{\text {th }}$ percentiles, means and two standard deviations of the data were derived.

Conclusion: These table and charts can be useful for accurate assessment of fetal femur length/abdominal circumference ratio to detect the type of fetal growth abnormality, symmetrical or asymmetrical. This study shows that there is similarity of this ratio with the western ratio unlike the individual fetal parameters.
\end{abstract}

Key words: Femur length/abdominal circumference ratio, Bangladesh.

\section{Introduction}

Ratio is a tool which shows if the fetal parts are growing proportionately or not. The most useful parameters are those that remain constant through some period, thus making them easier to remember. Ratios of the cranium are constant throughout the second and third trimesters. ${ }^{1}$

Various fetal ratios have been studied on western population. This ratio of fetal femur (FL) length with abdominal circumference (AC) is an important ratio to assess fetal growth. It gives an idea if the fetus is growing proportionately or not. The type of fetal growth restriction can be determined by it, whether it is symmetrical or asymmetrical. So far no study has been conducted on this ratio on Bangladeshi population.

In Bangladesh various studies have found that our fetal measurements are smaller than the Caucasian fetal measurements..$^{2-7}$ So we need reference tables from our own studies. This prospective study was carried out to produce a table with mean and 2 standard deviations (2SD) of this ratio based on our Bangladeshi population.

\section{Subjects and Method:}

This was a cross sectional study. It was conducted on pregnant ladies of 13 to 40 weeks gestational age. All study subjects were Bengalis. Structured questionnaires were filled up and well informed consent of the patients were obtained.
Inclusion criteria were- regular periods, no oral contraceptive for 3 months before conception, all patients gave a certain last menstrual period (LMP) date and had an ultrasound scan before 20 weeks gestational age to confirm the date within 2SD. No maternal malnutrition or any medical, surgical or obstetric complication and no uterine anomaly or large fibroid.

Ultrasonographic scans of fetal biparietal diameter (BPD), head circumference $(\mathrm{HC})$, abdominal circumference $(\mathrm{AC})$ and femur length (FL) using standard methodology were done on all patients who met the criteria. Electronic calipers were used for the measurements and they were made in mm. A $3.5 \mathrm{MHz}$ curvilinear transducer was employed for the ultrasound scans.

The technique of measuring the femoral length involves an initial determination of the lie of the fetus and locating the femur. Once the femur has been located, an attempt is made to define both ends of the calcified portion. The image is then frozen and with multidirectional electronic calipers, the calcified portion is measured. The aim is a femur which is finely outlined and has clear-cut ends. ${ }^{8}$ After 32 menstrual weeks, the distal femoral epiphysis is visible but not included in the measurements. ${ }^{9}$

Abdominal circumference measurements were obtained by tracing the appropriate circumference by calipers that open to the outline of fetal abdomen. 
The section was as round as possible with porto-caval confluence in the section appearing like a 'hockey stick' or J-shape.

For data entry and analysis SPSS program in computer software was used. The ratio between the two parameters was calculated. A table and a graph were prepared after regression analysis of the data. Values were expressed as percentiles, mean and 2 standard deviations, for the estimates in the table. A graph showing $3^{\text {rd }}, 10^{\text {th }}, 50^{\text {th }}, 90^{\text {th }}$ and $97^{\text {th }}$ percentiles was plotted on the raw data.

\section{Results}

Healthy pregnant ladies were included in this study after satisfying the required criteria. Sample size was 1223 subjects. Patient's demographics were as follows with mean and standard deviation (SD): Mean maternal age was $26.95( \pm 4.49)$ with range of 17 to 40 years. Mean BMI was found to be $23.67( \pm 3.4)$. Mean maternal height was $156.73( \pm 5.1) \mathrm{cm}$ and mean maternal weight in the first trimester was $57.92( \pm 9.2)$ kg. $96.9 \%$ were from middle class. $54.7 \%$ of the subjects were primipara and $45.3 \%$ were multipara.

Table I gives fitted percentiles of FL /AC ratio. It gives the number of cases in each week of gestation, the estimated values of $3^{\text {rd }}, 10^{\text {th }}, 50^{\text {th }}, 90^{\text {th }}$ and $97^{\text {th }}$ percentiles and the mean with 2 standard deviations of the data. In this study at 13 weeks gestational age mean FL/AC ratio was $0.20( \pm 0.03)$, at 36 weeks it was $0.23( \pm 0.02)$ and at 40 weeks it was $0.24( \pm 0.02)$. Range of ratio was $20-24$ or $22 \pm 2$. The coefficient of multiple correlation $R^{2}=0.454,(p<.001)$.

Table I

Fitted percentiles of femur length/ abdominal circumference (FL/AC) ratio. Estimated values after fitting the model

Fitted Percentiles of FL/AC ratio (estimated)

\begin{tabular}{lcccccccc}
\hline $\begin{array}{l}\text { Weeks of } \\
\text { gestation }(\mathrm{w})\end{array}$ & $\begin{array}{c}\text { No. of } \\
\text { fetuses }\end{array}$ & 3rd & 10th & 50th & 90th & 97 th & Mean & 2SD \\
\hline 13 & 15 & 0.17 & 0.18 & 0.20 & 0.22 & 0.23 & 0.20 & 0.03 \\
14 & 27 & 0.18 & 0.19 & 0.20 & 0.22 & 0.23 & 0.20 & 0.03 \\
15 & 32 & 0.18 & 0.19 & 0.21 & 0.23 & 0.24 & 0.21 & 0.03 \\
16 & 34 & 0.19 & 0.20 & 0.22 & 0.24 & 0.25 & 0.22 & 0.03 \\
17 & 27 & 0.20 & 0.20 & 0.22 & 0.24 & 0.25 & 0.22 & 0.03 \\
18 & 42 & 0.20 & 0.20 & 0.22 & 0.24 & 0.25 & 0.22 & 0.03 \\
19 & 34 & 0.20 & 0.20 & 0.22 & 0.24 & 0.25 & 0.22 & 0.03 \\
20 & 38 & 0.20 & 0.20 & 0.22 & 0.24 & 0.25 & 0.22 & 0.03 \\
21 & 43 & 0.20 & 0.20 & 0.22 & 0.24 & 0.25 & 0.22 & 0.03 \\
22 & 45 & 0.20 & 0.20 & 0.22 & 0.24 & 0.25 & 0.22 & 0.03 \\
23 & 39 & 0.20 & 0.20 & 0.22 & 0.24 & 0.25 & 0.22 & 0.03 \\
24 & 36 & 0.20 & 0.20 & 0.22 & 0.24 & 0.25 & 0.22 & 0.03 \\
25 & 42 & 0.20 & 0.20 & 0.22 & 0.24 & 0.25 & 0.22 & 0.03 \\
26 & 46 & 0.20 & 0.20 & 0.22 & 0.24 & 0.25 & 0.22 & 0.03 \\
27 & 44 & 0.20 & 0.20 & 0.22 & 0.24 & 0.25 & 0.22 & 0.03 \\
28 & 49 & 0.20 & 0.20 & 0.22 & 0.24 & 0.25 & 0.22 & 0.03 \\
29 & 50 & 0.20 & 0.20 & 0.22 & 0.24 & 0.25 & 0.22 & 0.03 \\
30 & 51 & 0.20 & 0.21 & 0.23 & 0.25 & 0.26 & 0.23 & 0.03 \\
31 & 52 & 0.20 & 0.21 & 0.23 & 0.25 & 0.26 & 0.23 & 0.03 \\
32 & 50 & 0.21 & 0.22 & 0.23 & 0.25 & 0.25 & 0.23 & 0.02 \\
33 & 55 & 0.21 & 0.22 & 0.23 & 0.25 & 0.25 & 0.23 & 0.02 \\
34 & 56 & 0.21 & 0.22 & 0.23 & 0.25 & 0.25 & 0.23 & 0.02 \\
35 & 59 & 0.21 & 0.22 & 0.23 & 0.25 & 0.25 & 0.23 & 0.02 \\
36 & 57 & 0.21 & 0.22 & 0.23 & 0.25 & 0.25 & 0.23 & 0.02 \\
37 & 54 & 0.21 & 0.22 & 0.23 & 0.25 & 0.25 & 0.23 & 0.02 \\
38 & 56 & 0.22 & 0.23 & 0.24 & 0.26 & 0.26 & 0.24 & 0.02 \\
39 & 55 & 0.22 & 0.23 & 0.24 & 0.26 & 0.26 & 0.24 & 0.02 \\
40 & 35 & 0.22 & 0.23 & 0.24 & 0.26 & 0.26 & 0.24 & 0.02 \\
\hline
\end{tabular}


Graph 1, shows the raw data for FL/AC ratio with fitted $3^{\text {rd }}, 10^{\text {th }}, 50^{\text {th }}, 90^{\text {th }}$ and $97^{\text {th }}$ percentile curves superimposed on it. The ratio was lower in early pregnancy, and then it rises up to a platform. The graph given is of $95 \%$ confidence interval $(\mathrm{Cl})$.

In the graph, the lowest curve gives the $3^{\text {rd }}$ percentile boundary, next curve gives $10^{\text {th }}$ percentile, next one gives $50^{\text {th }}$, next $90^{\text {th }}$ and the last curve gives $97^{\text {th }}$ percentile boundary of the data.

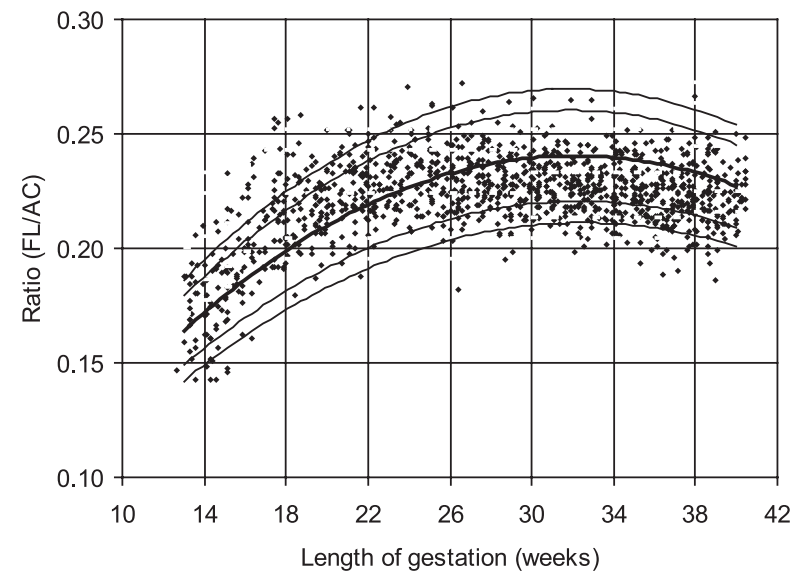

Graph 1: Raw data of femur length/ abdominal circumference (FL/AC) ratio with fitted $3^{\text {rd }}, 10^{\text {th }}, 50^{\text {th }}$, $90^{\text {th }}$ and $97^{\text {th }}$ percentile curves. It covers $95 \%$ of the population. The lowest curve gives the $3^{\text {rd }}$ percentile boundary, next curve gives $10^{\text {th }}$ percentile, next one gives $50^{\text {th }}$, next $90^{\text {th }}$ and the last curve gives $97^{\text {th }}$ percentile boundary.

\section{Discussion}

Ratios are an important method of comparing two parameters, as long as one of the parameters can be determined to be normal. Some ratios remain constant through some period, so they are easier to remember.

The estimated values after fitting a model were deduced. At 13 week gestational age mean FL/AC ratio was $0.20( \pm 0.03)$ and at 40 week it was 0.24 $( \pm 0.02)$ with $95 \%$ confidence interval of 0.22 to 0.26 . The coefficient of multiple correlation $R^{2}=0.454$, with a $p$ value of $<.001$.

The ratio in this study was more or less constant. At 13 week it was 20 and at 40 week it was 24 . That is, from 13 to 40 weeks the ratio was $20-24$ or $22 \pm 2$. The $3^{\text {rd }}, 10^{\text {th }}, 50^{\text {th }}, 90^{\text {th }}$ and $97^{\text {th }}$ percentile curves derived by fitting the model were superimposed on the observed raw data. Regression analysis was used and the quadratic model showed a good fit to the data.
This was similar to a western study where, at 21 week gestational age FL/AC was $0.20-0.24$ and at 40 week it was $0.20-0.24^{10}$, i.e. it was constant at $22 \pm 2$.

Femur length/abdominal circumference ratio is a timeindependent body proportionality ratio. Fetuses with FL/AC values less than $10^{\text {th }}$ centile and newborns with birth weights above $90^{\text {th }}$ percentile were classified as macrosomic, both prenatally and postnatally. ${ }^{11} \mathrm{It}$ was suggested that these parameters might better be applied in diabetic pregnancies where asymmetric macrosomia is more likely. ${ }^{12}$

Sonographic criteria for large for gestational age (LGA) in Diabetic mothers: performance characteristics of low FL/AC- Sensitivity is 58-79\%, specificity $75-80 \%$, Positive predictive value $68-83 \%$, and Negative predictive value $75-76 \% .{ }^{13}$

\section{Limitations}

One limitation was, this study was conducted in Dhaka city only, as it was carried out by one person. Another limitation was, the study population was predominantly of middleclass, as poor patients usually deliver at home and seldom go to see doctors.

\section{Conclusion and Recommendations}

Ultrasonography is an important tool to assess fetal growth, development and body proportionality. This study found that unlike individual fetal body parameters, this fetal ratio is the same as the western studies found. FL/AC was found to be $22 \pm 2$, from 13 40 weeks gestational age.

More such studies should be carried out on different parameters of the fetus to prepare Bangladeshi standards.

\section{References}

1. DuBose TJ. Size/ Age analysis. In: DuBose TJ (ed.), Fetal Sonography. $1^{\text {st }}$ Ed. Philadelphia, WB Saunders. 1996. p.95- 156.

2. Moslem F, Latifa S, Iffatara B, Shamsuddin AK, Nasreen M, Momen A, et al. Relation of BPD with gestational age in Bangladeshi fetus. Bangladesh J Ultrasonogr 1996; 3: 3- 8.

3. Bala KG. Ultrasound assessment of fetal BPD during normal pregnancy in Bangladeshi women and review of literatures. Bangladesh $\mathrm{J}$ Ultrasonogr 1991; 1 : 3.

4. Rashid S. Gestational age estimation from fetal Head circumference in Bangladesh. $11^{\text {th }}$ Congress of the World Federation for Ultrasound 
in Medicine and Biology (WFUMB), Seoul. Paper presented. J Ultrasound in Med and Biology. Clinical Obstetrics 2006; 32 (5S) 2361: 163.

5. Rashid SQ. Ultrasonic measurement of fetal abdominal circumference in context to Bangladeshi population. Bangladesh Med J 2000; 29: 36- 8.

6. Rashid SQ, Khatun S. A study of estimated fetal weights by ultrasound in Bangladesh and its correlation with Birth weights. J Bangladesh Coll Phys and Surg 2001; 19: 47- 51.

7. Rashid SQ. Fetal Biometry and Fetal weight in Bangladeshi population. Dissertation DMUD (USTC) 2002; 53- 69.

8. O'Brien GD, Queenan JT, Campbell S. Assessment of gestational age in the second trimester by real time ultrasound measurement of the femur length. Am J Obstet Gynecol 1981; 139: $540-45$.
9. Hadlock FP. Ultrasound determination of menstrual age. In: Callen PW(ed), Ultrasonography in Obstetrics and Gynecology. Philadelphia, PA. Saunders Co. 1994; p. 86-99.

10. Hadlock FP, Deter RL, Harrist RB, Roecker E, Park SK. A date- independent predictor of intrauterine growth retardation: Femur length/ abdominal circumference ratio. Am J Roentgenol 1983; 141: 979- 84.

11. Hadlock FP, Harrist RB, Fearneybough TC, et al. Use of the femur length/ abdominal circumference ratio in detecting the macrosomic fetus. Radiology 1985; 154: 503.

12. Modanlou HD, Komatsu G, Dorchester W, et al. Large for gestational age neonates: anthropometric reasons for shoulder dystocia. Obstet Gynecol 1982; 60: 417.

13. Bracero LA, Baxi LV, Rey HR, et al. Use of ultrasound in antenatal diagnosis of large-forgestational age infants in diabetic gravid patients. Am J Obstet Gynecol 1985; 152: 43. 